\title{
THE NOVEMBER MEETING IN GAINESVILLE
}

The five hundred eighty-fifth meeting of the American Mathematical Society was held at the University of Florida in Gainesville, Florida, November 17-18, 1961. There were 148 persons present, including 91 members of the Society.

By invitation of the Committee to Select Hour Speakers for Southeastern Meetings of the Society, Professor R. D. Anderson of Louisiana State University addressed the Society on the topic, Some structures of homeomorphisms.

Professors W. L. Strother and R. W. Ball presided at the sessions for contributed papers on Friday afternoon and Professors R. J. Koch and Trevor Evans presided at the sessions on Saturday morning.

Papers numbered (585-7) and (585-25) were not presented in person.

Athens, Georgia

G. B. Huff, Associate Secretary 